\title{
A HISTÓRIA ECONÔMICA DA AMAZÔNIA OITOCENTISTA EM SALA DE AULA: UM PROVEITOSO PERCURSO DE ANÁLISE E ENSINO*
}

Luiz Carlos Laurindo Junior

\section{Entre a prática docente e a reflexão historiográfica}

O debate sobre a economia da Amazônia no século XIX é uma constante nos cursos de graduação em História das instituições de ensino superior da região, especificamente nos ementários das disciplinas relacionadas com a história da Amazônia, nos quais duas obras clássicas comumente são encontradas: História econômica da Amazônia, de Roberto Santos (1980), e A borracha na Amazônia, de Bárbara Weinstein (1993). Na disciplina História da Amazônia II do curso de História da Universidade Federal do Oeste do Pará (Ufopa), ministrada por mim entre 2013 e 2015, essas obras compunham a bibliografia básica para o debate sobre a história econômica da Amazônia oitocentista, juntamente com um trabalho mais recente, a dissertação de mestrado de Luciana Batista (2004), Muito além dos seringais.

Trata-se de obras com profícuas interpretações sobre a economia amazônica, que oferecem os alicerces para pensarmos as mudanças estruturais e conjunturais entre os séculos XVIII e XIX, o impacto da cabanagem na economia, a configuração das formas e das relações de trabalho, a diversidade econômica da região e, ao mesmo tempo, a proeminência do cacau na primeira metade do século XIX e da borracha na segunda - commodity de destaque na pauta de exportações do Império do Brasil, cuja produção e exportação estimularam variado conjunto de mudanças, matizaram a passagem do Império para a República na região, bem como aumentaram as prospecções de lucros e o ideal de desenvolvimento das elites econômicas até o início do século XX. Entretanto, há uma ausência marcante e característica nesses trabalhos: o capitalismo. Nenhum dos supracitados autores entende a economia da região no século XIX

$\overline{{ }^{*} \mathrm{DOI}-10.29388 / 978}$-65-86678-64-2-0-f.153-168

1 Professor efetivo do curso de História da Universidade Federal do Oeste do Pará (Ufopa), atuando na área de História da Amazônia, mestre em História pela Universidade Federal do Pará (Ufpa) e doutorando em História Social pela Universidade de São Paulo (USP). O presente trabalho foi realizado com apoio da Coordenação de Aperfeiçoamento de Pessoal de Nível Superior (Capes) — Código de Financiamento 001. 
como parte do sistema mundial capitalista, o que limita tanto a compreensão de alguns de seus aspectos - como a dinamização e a continuidade da escravidão negra de origem africana - quanto o balizamento da Amazônia no âmbito da economia mundial.

No presente texto, elenco as potencialidades e os limites das análises desenvolvidas por Santos, Weinstein e Batista, e, baseado em certa perspectiva teórica, proponho outro percurso para a análise da economia da região no século XIX, que, devidamente conduzido na licenciatura em História e transposto para o ensino básico, pode suprir algumas lacunas sobre o tema. Pode ainda fomentar proveitoso diálogo entre passado e presente, pois entender as especificidades da inserção da região no sistema capitalista do século XIX possibilita-nos vislumbrar nuances outras da Amazônia no redimensionado capitalismo do século XX.

\section{Uma economia dinâmica e diversificada, atrelada ao sis- tema mundial capitalista}

A abertura do rio Amazonas à navegação a vapor (1852) e à navegação internacional (1867) foi medida adotada pelo Império do Brasil, sob a perspectiva livre-cambista, para ampliar as redes de transporte internas, aumentar a participação da região no mercado mundial de commodities do século XIX e fomentar sua inserção no sistema mundial capitalista, medidas equivalentes ao estrondoso aumento da malha ferroviária do Sudeste. A navegação a vapor foi uma revolução no âmbito da circulação, dando maior vazão à produção e à comercialização de diversas mercadorias no mercado interno (regional e nacional) e externo, pois diminuiu o tempo de transporte, barateou custos e viabilizou a expansão em espaço e volume das mercadorias produzidas (Lopes, 2002). Favoreceu, portanto, as commodities que dominaram a pauta de exportações da província do Pará no século XIX: o cacau e a borracha.

Durante as quatro décadas finais do Império (e da escravidão negra), enquanto houve acentuado aumento da exportação de borracha (em quantidade e em valor exportado), principalmente a partir da década de 1860, as exportações de cacau, produto majoritariamente agrícola a partir de meados do XIX, mantiveram-se constantes. Ou seja, o agigantamento da borracha não abalou o lugar do cacau na pauta de exportações, revelando a coexistência entre agricultura e extrativismo (Sampaio, 1997; Batista, 2004; Bezerra Neto, 2009; Barroso e Laurindo Jr., 2017), tanto que, entre 1847 e 1888, o ápice da exportação de ca- 
cau deu-se no período em que a exportação de borracha atingiu os maiores valores, de 1878 a 1886 (Laurindo Jr., 2018). Em decorrência desse atrativo quadro econômico, a população livre cresceu exponencialmente — em razão do afluxo de migrantes para o Pará, oriundos da região atualmente conhecida como Nordeste — , e a população escrava — ampliada pelo tráfico transatlântico (até 1850), pelo tráfico interno e pela reprodução endógena (até 1871) — foi estabilizada na faixa dos 30 mil indivíduos (Bezerra Neto, 2012; Laurindo Jr., 2012; Barroso, 2017).

A borracha passou a ser produzida em quase todo município da região. No detalhado balanço econômico da província feito no relatório da presidência provincial de 1862, entre os 26 municípios elencados, em 14 são contabilizadas a produção e a exportação de borracha. O cacau apresentou disseminação semelhante, aparecendo em 16 municípios (Pará, 1862). Concomitantemente ao espraiamento, houve concentração e territorialização dessas commodities em alguns espaços, em virtude de condições econômicas, sociais ou naturais propícias à sua produção e comercialização. A produção de borracha estava concentrada na região da foz do rio Amazonas, no Marajó e, a partir de meados da década de 1880, também na comarca da Capital; a do cacau, no Baixo Amazonas e na região do rio Tocantins (Pará, 1885; Laurindo Jr., 2018).

As regiões mais próximas do oceano Atlântico e da fronteira com o Maranhão (comarcas da Capital, de Vigia e de Bragança) produziram as menores quantidades de cacau e borracha entre as décadas de 1860 e 1880 . Em seus municípios, prevaleceu a produção de outras mercadorias para exportação e para o mercado interno, sobretudo para o abastecimento, destacando-se o açúcar, a aguardente, o arroz pilado e com casca, o tabaco, a farinha, peixe e derivados, gado e derivados (Pará, 1862, 1885). Afinal, com o boom da borracha e o aumento populacional, a demanda por alimentos também cresceu, atraindo investidores e negociantes (Batista, 2004; Macêdo, 2009) e absorvendo significativa fatia da população livre e escrava da província como força de trabalho.

As autoridades da província do Pará costumavam alardear que a borracha estava tomando os braços da lavoura e minando a economia da província, sobretudo a produção de subsistência e abastecimento. Todavia, esses discursos expressam os interesses de determinados grupos e traduzem um projeto de poder e nação específico, que enxergava na agricultura um mecanismo de modernização e civilização dos modos de vida na região, capaz de assegurar a propriedade e o povoamento regular, a ser capitaneado pelo Estado brasileiro e pelas forças políticas da região (Nunes, 2011). Os próprios relatórios da presidência provincial da segunda metade do século mostram uma economia cada vez mais 
dinâmica, em razão da larga produção-exportação do cacau e da borracha, que conectou a região mais fortemente à economia mundial e desdobrou-se em intensa diversificação da economia provincial. Mesmo nos municípios onde se concentrava a produção do cacau e da borracha, várias outras mercadorias eram produzidas. Inversamente, nas regiões economicamente atreladas ao mercado interno, geralmente havia alguma produção de cacau e borracha (Pará, 1862, 1885).

Diferentes tipos de embarcação rasgavam as vias fluviais e teciam as redes comerciais, por meio das quais as mercadorias eram escoadas, redes que foram alargadas e solidificaram-se ao longo da segunda metade do XIX, elemento representativo da dinamização. As embarcações movidas a vapor foram a face mais decisiva desse processo, mas não a única. Entre 1861 e 1876, houve o aumento de 5 para 23 vapores circulando por águas paraenses, ao mesmo tempo que as duas outras principais embarcações responsáveis pelo transporte de grande tonelagem passaram a circular em maior número e com maior frequência: as alvarengas aumentaram de 6 para 21, e as canoas, de 157 para 519 (Pará, 1862, 1877). Não à toa, os chamados regatões, comerciantes que faziam de suas embarcações verdadeiros estabelecimentos comerciais, ligando os centros urbanos às áreas deles afastadas, fazendo a ponte entre os municípios que eram parte e os que estavam à margem das rotas de navegação a vapor, adentrando vias fluviais de difícil acesso, chamavam a atenção das autoridades e, apesar das reiteradas medidas controladoras e inibidoras de suas atividades, transportavam grande quantidade de mercadorias, pessoas e ideias (Lopes, 2002; Cardoso, 2017).

Quando o vale amazônico despontou no mercado mundial, não demorou para que a "navegação de longo curso" passasse a ser dominada pelos Estados Unidos e, majoritariamente, pelo Império Britânico. Em 1867, a Grã-Bretanha foi o destino do maior valor de mercadorias exportadas do Pará (aproximadamente 3.250 contos de réis), seguida pelos Estados Unidos pós-Guerra Civil (3.224) e pela França (2.013) (Sales, 2017, p. 162). Os destinos do cacau e da borracha reafirmam a dominância. No exercício financeiro de 1876-1877, por exemplo, a exportação de borracha para a Grã-Bretanha equivaleu a aproximadamente 5.538 contos de réis; para os Estados Unidos, a 4.036 contos de réis; e, para a França, a 297 contos de réis. Por outro lado, a França monopolizou o mercado do cacau, recebendo o equivalente a 1.118 contos de réis contra exportação nula para os outros dois. Em 1878, o padrão de exportação repetiu-se, tendo, porém, sido contabilizada alguma exportação de cacau para a Grã-Bretanha e os Estados Unidos. Portanto, enquanto a França dominava a exportação 
amazônica do cacau, a Grã-Bretanha e os Estados Unidos dominavam a de borracha (Pará, 1878, 1879; Santos, 1980; Weinstein, 1993).

As entradas de embarcações no porto de Belém entre as décadas de 1840 e 1860 confirmam o fortalecimento dos contatos comerciais da província com os mercados nacional e mundial e também traduzem a progressiva predominância dos britânicos. Enquanto, entre 1840 e 1851, entraram no Pará 209 embarcações vindas de portos brasileiros e 645 de fora do Brasil, no intervalo de 1857 a 1867 os números subiram para 421 e 777, respectivamente. Entre as embarcações oriundas de portos estrangeiros, as britânicas saltaram de aproximadamente $12 \%$, no período de $1840-1846$, para 37,8\%, em 1857-1867, superando as portuguesas e americanas, até então majoritárias (Sales, 2017, p. 157). A Guerra de Secessão explica essas mudanças de posição, e, quando findada, embora os estadunidenses tenham voltado a disputar espaços de influência com os britânicos, não conseguiram retomar a hegemonia sobre a navegação de longo curso na região.

A Grã-Bretanha era, conforme Giovani Arrighi, o centro do então ciclo sistêmico de acumulação de capitais, ao qual a economia do Vale do Amazonas foi atrelada. Os ciclos sistêmicos de acumulação de capital, para o autor, em interlocução direta com Fernand Braudel, são capitaneados por uma "camada superior 'não especializada' da hierarquia do mundo do comércio", em que são feitos os "lucros em larga escala", e retratam "não apenas a lógica dos investimentos capitalistas individuais, mas também um padrão reiterado do capitalismo histórico como sistema mundial". Arrighi identifica quatro grandes ciclos sistêmicos ao longo do tempo, organizados em torno de centros de acumulação situados em diferentes lugares, com variadas características, temporalidades e abrangências. Além do britânico, situado entre a segunda metade do século XVIII e o início do século XX, existiram outros três: o genovês (séculos XV ao XVII), o holandês (fim do século XVI ao XVIII) e o norte-americano (fim do século XIX até a presente fase de expansão financeira). A disputa entre os Estados Unidos e o Império Britânico pela dominância sobre as commodities da Amazônia, por conseguinte, pode ser vista como sintomática da hegemonia do segundo, mas também da ascensão do primeiro, desdobramento da mudança entre um ciclo e outro (Arrighi, 2013, p. 5-9).

Quanto mais tipos e maiores quantidades de mercadorias eram produzidos e comercializados dentro da província, entre províncias e entre a região e o mercado mundial, maior era, de um lado, a circulação de capitais, o lucro dos que controlavam a produção e o comércio, as rendas da província, a disponibilidade de crédito e, do outro e em última escala, o reinvestimento nos principais 
produtos da pauta de exportação, na miríade de atividades econômicas desenvolvidas ao longo de todo o Vale, mas também nos serviços urbanos e na incipiente (porém não insignificante) produção industrial. Essa é outra característica inerente à dinamização. O aumento dos lucros e da circulação de capitais e créditos pode ser medido pela multiplicação das grandes casas comerciais e firmas aviadoras, o crescimento do setor bancário e a atuação de companhias de seguro, estrutura financeira garantidora da liquidez da economia e da rede de endividamento (ou aviamento) inerente ao boom da borracha (Weinstein, 1993). Simultaneamente, formaram-se mais e maiores fortunas a partir de meados do século, baseadas em variados bens (terras, escravos, imóveis urbanos, entre outros), o que também demonstra que os negócios da borracha não constituíam a única fonte de acumulação e investimento (Batista, 2004; Cancela, 2006; Sales, 2017). No âmbito do Estado, entre o final da década de 1830 e a década de 1880, a arrecadação da alfândega do Pará e a renda interna da província cresceram significativamente (Santos, 1980; Weinstein, 1993; Sales, 2017).

Em relação ao reinvestimento dos capitais acumulados, as áreas mais urbanizadas eram alvo comum da aplicação de capitais do Estado e da iniciativa privada no melhoramento da infraestrutura urbana e no setor de serviços em geral, questão abordada em inumeráveis trabalhos. Dois deles destacam-se pelo pioneirismo e por abordarem questões centrais, relativas à constituição das duas metrópoles amazônicas do século XIX: Belém e Manaus. Enquanto Maria de Nazaré Sarges (2002) aborda o projeto de modernidade arquitetado pelas elites na capital do Pará e o papel das autoridades públicas nas mudanças então em voga, Edinea Dias (2007) demonstra que a urbanização de Manaus, em compasso com aquele tempo, tinha caráter higienizador, visando a limpar a arquitetura e a população da cidade, e foi marcada pela interferência do capital privado no espaço público. Ainda segundo as autoras, as duas cidades foram enredadas em uma aura civilizacional, essencialmente excludente, norteadora de determinados projetos políticos, econômicos e culturais dos grupos que se revezavam no poder.

Extrapolando a esfera dos centros urbanos, para as elites, a produção agrícola e a industrial representavam outro horizonte de investimentos e de desenvolvimento econômico nos quadros da civilização (Weinstein, 1993; Nunes, 2011). Esse era o mote por trás dos insistentes debates e das reclamações relativas ao extrativismo e à ausência de trabalho regular (Oliveira Filho, 1979), bem como dos constantes balanços econômicos feitos pela presidência provincial. $\mathrm{O}$ balanço de 1862, intitulado "Indústria", é um bom exemplo, pois se inicia com a queixa de que "a indústria nesta província está ainda em sua infância" e logo 
em seguida arrola as atividades econômicas de cada município, deixando subentendido o patamar civilizacional alcançado por cada um. A capital, onde predominaram atividades econômicas voltadas ao mercado interno, aparece em primeiro lugar na lista, com vários estabelecimentos agrícolas e industriais: engenhos de açúcar e aguardente, de café, de serrar madeiras, de socar e pilar arroz, olarias de tijolos e telhas, fábricas de farinha, cal, louça, extração de óleos, curtume, sabão e chocolate (Pará, 1862). Ou seja, as mesmas vozes que, ocasionalmente, levantavam-se contra a goma elástica e outros produtos extraídos da floresta versavam positivamente sobre o alargamento e a diversificação da economia, que, se não fosse a dinamização pela produção-exportação de cacau e borracha e a inserção mais vigorosa da região no mercado mundial, dificilmente teria acontecido.

Não obstante todos esses indícios de que a economia da província do Pará e da Amazônia havia encontrado maré favorável no século XIX, de que se tornara dinâmica, três interpretações delineadas nas três obras indicadas no início do texto, recorrentemente reproduzidas na historiografia, no ensino de história, no meio memorialista e no senso comum, ao mesmo tempo reforçam e relativizam essa dinamicidade. Daqui em diante, analisaremos as bases dessas interpretações, objetivo central do presente texto.

\section{Relendo e reformulando interpretações}

Em A borracha na Amazônia, Bárbara Weinstein (1993) entende que a dinamização da economia foi um desdobramento do crescimento do setor comercial, mas não implicou transformações estruturais e não foi capaz de inserir a economia da região no sistema mundial capitalista, caracterizado pela indústria metropolitana. A autora compara a economia da borracha com a economia cafeeira de São Paulo e explica a suposta estagnação estrutural pelo fato de que o boom da borracha (para ela acontecido apenas na década de 1870) foi marcado pela concentração das benesses em poucas mãos, pelo foco exacerbadamente direcionado à borracha por parte dos detentores de capital, pelo forte controle e coerção sobre os produtores e pela conservação de um "sistema primitivo" de produção e de troca, responsáveis por manter a região atrelada a uma lógica pré-capitalista. Desconsiderando as variâncias do capitalismo no tempo e no espaço e adotando como critério de sua definição os espaços de produção de forma isolada, a lógica do capital estaria vinculada ao desenvolvimento de relações de produção específicas, baseadas no trabalho assalariado e na implementação 
de fábricas. Logo, em que pese a dinamização, no século XIX, a região ainda não teria se enquadrado nesse arquétipo.

Weinstein dialoga com Ernesto Laclau, situado em um quadro teórico cujo arco vai de Maurice Dobb a Robert Brenner e que, segundo Dale Tomich (2011, p. 62), "enfatiza o primado das relações sociais na determinação tanto do caráter de um determinado modo de produção quanto dos resultados contingentes das lutas de classe na determinação da transição de um modo para outro". Robert Brenner, ainda segundo Tomich (2011, p. 61-64), identifica o capitalismo com a relação entre capital e trabalho assalariado, base do desenvolvimento econômico capitalista, única teoricamente capaz de generalizar a produção de mercadorias por permitir o desenvolvimento das forças produtivas por meio da inovação tecnológica e da produtividade crescente do trabalho; caracteriza de forma seccionada as relações de classe em capitalistas, pré-capitalistas ou não capitalistas, conforme a presença ou não do assalariamento; e atribui papel secundário ao mercado, "exterior às relações prevalentes de produção direta". Para Tomich (2011, p. 48-51), não há dicotomização entre produção e mercado no capitalismo, e a mercadoria é o nexo entre a produção, a distribuição, a troca e o consumo em um campo unificado de conceitos relacionais, cada qual definido mediante sua relação com os demais.

A incessante acumulação de capital e a ampla mercantilização dos processos de produção, troca e investimento, realizadas na escala de uma economia-mundo e permeadas pelas estruturas estatais, constituem a essência do que Immanuel Wallerstein (2011) chama sistema-mundo capitalista, existente e em expansão desde o século XVI. Wallerstein (2011) também quebra com a dicotomização entre produção e mercado e com as relações entre capital e indústria e entre capital e assalariamento, contribuindo enormemente para o entendimento da historicidade e da alternância do capitalismo. Esse é o ponto que possibilita a observação mais acurada, por exemplo, das interconexões no tempo e no espaço entre as Américas, perpassadas pela influência recíproca entre as partes e o todo, pautadas pelo recurso a diferentes e entrecruzadas relações de trabalho. Voltando a Tomich (2011, p. 76-77), a economia mundial incorporou, ao longo do tempo, "zonas geográficas e ambientes naturais específicos [...] transformados por processos materiais de produção seletivos, organizados mediante formas particulares de relações de produção". Por meio da divisão do trabalho e do mercado, as particularidades interagem entre si, sendo a organização do trabalho "constituída em relação a outros processos materiais e formas sociais de produção". Em síntese, "cada forma individual é simultaneamente constitutiva do sistema global e de uma manifestação particular dos seus processos". 
Tendo por base essas considerações, outra percepção da economia paraense do século XIX que merece ressalvas é a reproduzida no importante trabalho de Luciana Batista (2004), Muito além dos seringais. A autora, em diálogo com Karl Polanyi, classifica a economia da província como pré-industrial, pois seria marcada por baixa liquidez, baixa circulação de mercadorias e frágil divisão do trabalho. Diferentemente das economias de mercado, nas economias préindustriais a busca do lucro e a "salvaguarda de bens materiais" não seriam es senciais, predominando entre os indivíduos os "interesses relativos à proteção de sua situação social". No Pará, o trabalho e a terra não teriam passado por processo de mercantilização; os bens materiais em geral seriam mais valorosos por agregarem prestígio social ou por garantirem a subsistência do que propriamente pelo valor econômico a eles agregados. A aplicação e o reinvestimento de capitais, portanto, escapariam da lógica da produtividade e lucratividade em prol da reiteração de uma "hierarquia social desigual", da construção e consolidação de alianças sociais em razão do "prestígio social". Isso explicaria as alianças parentais e de amizade entre os grupos ligados à agricultura e ao comércio, bem como o não abandono da agricultura no início da expansão produtiva da borracha (Batista, 2004, p. 19-21).

Essa percepção também deriva da interlocução com a obra dos historiadores João Fragoso e Manolo Florentino, O arcaísmo como projeto, que relativiza os impactos da crise de fins do século XVIII, no Brasil, e enfatiza a qualidade não capitalista e arcaica de sua economia, desdobramento da predominância de elementos do Antigo Regime ibérico na conformação daquela sociedade. Em crítica ao livro, Rafael Marquese (2013, p. 238-246) afirma que ele reifica a dicotomia entre externo e interno, a fim de valorizar o segundo e construir, a partir daí, uma análise focada essencialmente no que é "de dentro", como faz Batista, que diminui bruscamente a influência dos movimentos mais amplos da economia mundial, à qual o Pará estava atrelado, e superdimensiona a autonomia da economia provincial. A patente busca de lucro e acumulação na região é colocada como pano de fundo, bem como o dinamismo derivado de vários fatores reconhecidos pela autora, quais sejam, a contínua produção e exportação de cacau, o boom da borracha e o alargamento das redes comerciais - fatores que, inclusive, explicam as alianças entre as elites identificadas por ela, em parte arquitetadas por meio do casamento (Cancela, 2006). A dinamização econômica, por outro lado, é a chave de entendimento da continuidade da produção agrícola, juntamente com as estratégias discursivas e os projetos políticos e civilizacionais que direcionavam as falas e as ações das elites e autoridades provinciais (Nunes, 2011). 
Quanto ao boom da borracha, a ampliação de sua demanda no mercado mundial, como destaca João Pacheco de Oliveira Filho (1979), deu margem a um remodelamento do processo produtivo nos seringais, antes explorados com força de trabalho mobilizada na própria região, geralmente em bases familiares, simultaneamente à produção de outros itens para a subsistência e o mercado interno, com baixa produtividade por pessoa. Após o boom, a força de trabalho utilizada passou a ser predominantemente importada; o trabalho, desenvolvido isoladamente na floresta; a produção, essencialmente monocultora; e a produtividade do trabalhador foi elevada. João Pacheco esquematizou essa passagem entre um modelo de organização e outro, chamados por ele "modelo caboclo" e "modelo do apogeu". Apesar da generalização inerente à construção de modelos, o autor consegue captar os aspectos centrais da mudança no processo produtivo, efetivada por meio do controle da terra e da propriedade, do controle do capital - concentração dos meios de financiamento da produção e comercialização em poucas mãos e subordinação do "caboclo amazônico" às determinações do grande capital - e do aumento do controle da força de trabalho - apelando-se à migração de trabalhadores do Nordeste em razão da plasticidade do trabalho do produtor local e do lento crescimento vegetativo na região.

Nesse quesito, uma terceira e importante interpretação da economia da região também merece releitura. Em História econômica da Amazônia, Roberto Santos (1980) destaca que uma das condições para que a região saísse do suposto impasse em que se encontrava em meados do século XIX — falta de solidez e baixa renda per capita - seria superar a escassez crônica de mão de obra, superação concretizada com a chegada massiva à região de migrantes oriundos do Nordeste, transformados em "braço de sustentação da atividade extrativa e agrícola”. A partir do que apresentam João Pacheco (1979) e Francivaldo Nunes (2011), os constantes discursos das elites políticas e econômicas acerca da insuficiência geral de força de trabalho na província, da absurda absorção de trabalhadores na produção da borracha e do necessário recurso à imigração podem ser entendidos menos como reflexo de uma suposta escassez de força de trabalho estranguladora da economia e mais como estratégia para alimentar mais incisivamente o mercado de trabalho, para explorar mais eficazmente os trabalhadores e exercer maior controle sobre eles, para colocar em prática determinado projeto de desenvolvimento econômico, ampliar a margem lucros e, sim, reforçar a hierarquia social existente, como pontua Luciana Batista (2004).

Na própria análise de Santos (1980, p. 70-73) aparecem evidências disso, quando afirma que "não ocorreu, até 1872, um declínio absoluto da produ- 
ção de todos os principais gêneros registrados estatisticamente", mas que o ritmo de crescimento dessa produção fora inferior ao da população, visto a atratividade exercida pela economia gomífera nos trabalhadores ingressados na província e o comum direcionamento dos migrantes para os seringais. Portanto, baseando-se nas maiores exigências alimentares derivadas do aumento populacional, sem informações sólidas sobre a economia de subsistência e abastecimento ou o movimento das importações de outras províncias, afirma que a região foi obrigada a recorrer às importações (de outros países?) para suprir sua demanda por alimentos. Se, efetivamente, ocorreram deslocamentos populacionais entre diferentes atividades econômicas, como pontua o autor, não há evidências de que eles afetaram de forma substantiva a produção para subsistência e abastecimento, nem as importações e exportações de variados gêneros além da borracha (Batista, 2004). Por fim, o problema da hipotética carência generalizada de braços era que, nas palavras do próprio Santos (1980), “o potencial produtivo da Amazônia, [...] em termos de borracha, era extremamente subaproveitado na primeira metade dos anos setenta".

Saindo da seara do trabalho livre, as obras de Roberto Santos (1980), Bárbara Weinstein (1993), Luciana Batista (2004) e de outros estudiosos da economia da Amazônia no século XIX ignoram ou tratam como irrelevante a continuidade da escravidão negra, seja pela suposta inexpressividade numérica da população escrava, seja pela aparente incompatibilidade entre escravismo e extrativismo. Já foi densamente ponderado pela historiografia que a população escrava foi relativamente estável ao longo daquele século, vindo a diminuir apenas nos primeiros anos da década de 1880, e essa força de trabalho foi absorvida em variadas atividades econômicas, tendo sido transacionada nas e entre as áreas produtoras de cacau e borracha, as regiões voltadas ao mercado interno e os núcleos urbanos (Bezerra Neto, 2012; Laurindo Jr., 2012; Barroso, 2017).

Fundamental para entendermos a continuidade do escravismo na região e essa estabilidade da população escrava no século XIX é a noção de que capitalismo e escravidão foram indissociáveis em vários espaços americanos naquele século, principalmente no sul dos Estados Unidos, em Cuba e no Brasil (Williams, 2012; Tomich, 2011; Blackburn, 2011; Franco, 1984; Marquese e Salles, 2016), século em que o Vale do Amazonas, imerso na economia mundial capitalista, aproximou-se da hegemônica Grã-Bretanha e teve sua economia dinamizada. Como pontua Dale Tomich (2011, p. 48-51), a divisão mundial do trabalho, "historicamente formada como uma relação entre processos materiais específicos e formas sociais de trabalho em lugares particulares, integrados pelo mercado mundial", revelou a "totalidade complexa, multidimensional e estrutu- 
rada das relações que formam a economia mundial capitalista". Logo, não é de se estranhar que a escravidão e outras formas de trabalho não assalariadas possam ser integradas em dados contextos. Maria Sylvia de Carvalho Franco (1984, p. 160, 174) também não vê incompatibilidade nessa integração, pois, "para que a força de trabalho apareça como mercadoria, como objeto de compra e venda, não é condição necessária que o trabalhador seja livre", e, "sendo requisito para a formação de mais-valia que a força de trabalho seja mercadoria, o capital torna-se compatível com outros regimes de trabalho desde que $[\ldots]$ constituído um mercado de força de trabalho". Em sua concepção, o desenvolvimento do capitalismo teve uma "determinação universal" (o lucro e a acumulação), multifacetada em partes distintas e formas particulares.

À disposição das elites econômicas e dos pequenos e médios produtores paraenses que precisavam de trabalhadores estava um mercado de trabalho diversificado, composto por indígenas de diferentes grupos étnicos, negros livres, libertos e escravos, brancos pobres, mestiços de variadas feições e cores, paraenses ou migrantes de outras províncias e países, todos submetidos a variadas formas e relações de trabalho. Segundo Marcel van der Linden (2013, p. 3040), nas sociedades inseridas na lógica capitalista, também costumam existir formas de mercantilização da força de trabalho situadas em zonas intermediárias entre o trabalho assalariado, o trabalho autônomo, a escravidão e o lumpemproletariado. $\mathrm{Na}$ Amazônia, como em outras partes do Império, embora isso tenha sido comum e as experiências no mundo do trabalho possam ter aproximado trabalhadores livres e escravos (Bezerra Neto, 2009; Laurindo Jr., 2012), proximidade, inclusive, que influenciou as relações de trabalho em geral, havia claras diferenças entre uma e outra condição, o que Linden acaba negligenciando ao homogeneizar a diversidade sob o conceito de "trabalhadores subalternos". No Pará oitocentista, o fato de a presença específica de escravos de origem africana ter se conformado como continuidade interferiu diretamente na constituição de seu complexo mundo e mercado do trabalho.

\section{Considerações finais}

Enxergar a Amazônia oitocentista como parte do sistema mundial capitalista é um ganho analítico e conceitual para a compreensão da economia da região, estruturada na longa duração e redimensionada no século XIX, marcada por três características principais, que precisam ser encampadas nas aulas de história da Amazônia: a sazonalidade da produção; a simultaneidade entre os ti- 
pos de atividade desempenhadas (extrativismo, agricultura, pecuária, pesca e caça); e o uso de diferentes formas de trabalho nos espaços produtivos, às vezes concomitantemente. Elas contrariam a percepção equivocada — cristalizada na historiografia até a década de 1990 e ainda comum em certos materiais didáticos e memorialísticos — de que as características geográficas da região e as flutuações dos preços das commodities no mercado teriam inibido o desenvolvimento da produção agrícola, bem como a visão de que a sociedade local não teria cabedal técnico ou cultural suficiente para aprimorar a agricultura, situações que teriam direcionado os esforços das elites locais e dos produtores diretos ao extrativismo.

Fatores de ordem econômica (como os movimentos do mercado mundial, a disponibilidade de capital, o mercado de trabalho, entre outros), cultural (a cosmogonia das comunidades, o hábito de procurar ou criar determinados animais, coletar ou plantar determinados vegetais), política (os momentos de instabilidade ou estabilidade, a presença e a influência do Estado) e ambiental (o regime de chuvas, as cheias e vazantes dos rios, a qualidade dos solos) influenciaram a opção pelo investimento em determinada atividade econômica, o tempo a ser nela despendido e a força de trabalho a ser empregada. Exemplo disso é a coexistência, no Pará, do boom da borracha, da continuidade da produção de cacau e outros produtos para o mercado interno e externo com a produção de subsistência, recorrendo-se ao trabalho escravo ou livre (sob variadas relações de trabalho). Atividades, em todo caso, travejadas, direta e indiretamente, pelo capitalismo.

\section{Referências}

ARRIGHI, Giovanni. O longo século XX: dinheiro, poder e as origens de nosso tempo. Rio de Janeiro: Contraponto, 2013.

BARROSO, Daniel S. O cativeiro à sombra: estrutura da posse de cativos e família escrava no Grão-Pará (1810-1888). 2017. Tese (Doutorado em História Econômica), Universidade de São Paulo, São Paulo, 2017.

. ; LAURINDO JR., Luiz C. À margem da segunda escravidão? A dinâmica da escravidão no vale amazônico nos quadros da economia-mundo capitalista. Revista Tempo, Niterói, v. 23, n. 3, p. 568-588, set./dez. 2017. 
BATISTA, Luciana Marinho. Muito além dos seringais: elites, fortunas e hierarquias no Grão-Pará, c. 1850-c. 1870. 2004. Dissertação (Mestrado em História), Universidade Federal do Rio de Janeiro, Rio de Janeiro, 2004.

BEZERRA NETO, José Maia. Escravidão negra no Grão-Pará (séculos XVII-XIX). 2. ed. Belém: Paka-Tatu, 2012.

. Por todos os meios legítimos e legais: as lutas contra a escravidão e os limites da Abolição (Brasil, Grão-Pará: 1850-1888). 2009. Tese (Doutorado em História), Pontifícia Universidade Católica de São Paulo, São Paulo, 2009.

BLACKBURN, Robin. The American crucible: slavery, emancipation and human rights. Londres: Verso, 2011.

CANCELA, Cristina Donza. Casamento e relações familiares na economia da borracha (Belém, 1870-1920). 2006. Tese (Doutorado em História Econômica), Universidade de São Paulo, São Paulo, 2006.

CARDOSO, Antonio Alexandre Isidio. O eldorado dos deserdados: indígenas, escravos, migrantes, regatões e o avanço rumo ao oeste amazônico no século XIX. 2017. Tese (Doutorado em História Social), Universidade de São Paulo, São Paulo, 2017.

DIAS, Edinea M. A ilusão do fausto: Manaus, 1890-1920. 2. ed. Manaus: Valer, 2007.

FRAGOSO, João; FLORENTINO, Manolo. O arcaismo como projeto: mercado atlântico, sociedade agrária e elite mercantil em uma economia colonial tardia: Rio de Janeiro, c. 1790-c. 1840. Rio de Janeiro: Civilização Brasileira, 2001.

FRANCO, Maria Sylvia de Carvalho. Organização social do trabalho no período colonial. In: PINHEIRO, Paulo Sérgio (coord.). Trabalho escravo, economia e sociedade. Rio de Janeiro: Paz e Terra, 1984.

LAURINDO JR., Luiz C. A cidade de Camilo: escravidão urbana em Belém do Pará (1871-1888). 2012. Dissertação (Mestrado em História), Universidade Federal do Pará, Belém, 2012.

. , Luiz C. Rios de escravos: capitalismo, escravidão e tráfico interno no Vale do Amazonas (1840-1888). 2018. Relatório de Qualificação (Doutorado em História Social), Universidade de São Paulo, São Paulo, 2018.

LINDEN, Marcel van der. Trabalhadores do mundo: ensaios para uma história global do trabalho. Campinas: Unicamp, 2013. 
LOPES, Siméia de Nazaré. O comércio interno no Pará oitocentista: atos, sujeitos sociais e controle entre 1840-1855. 2002. Dissertação (Mestrado em Planejamento e Desenvolvimento), Universidade Federal do Pará, Belém, 2002.

MACÊEO, Sidiana da Consolação Ferreira de. Daquilo que se come: uma história do abastecimento e da alimentação em Belém (1850-1900). 2009. Dissertação (Mestrado em História), Universidade Federal do Pará, Belém, 2009.

MARQUESE, Rafael de Bivar. As desventuras de um conceito: capitalismo histórico e a historiografia sobre a escravidão brasileira. Revista de História, São Paulo, n. 169, p. 223-253, jul./dez. 2013.

. ; SALLES, Ricardo (org.). Escravidão e capitalismo bistórico no século XIX:

Cuba, Brasil e Estados Unidos. Rio de Janeiro: Civilização Brasileira, 2016.

NUNES, Francivaldo A. Sob o signo do moderno cultivo: Estado imperial e agricultura na Amazônia. 2011. Tese (Doutorado em História), Universidade Federal Fluminense, Niterói, 2011.

OLIVEIRA FILHO, João Pacheco de. O caboclo e o brabo: notas sobre duas modalidades de força-de-trabalho na expansão da fronteira amazônica no século XIX. Encontros com a Civilização Brasileira, v. 11, p. 101-140, maio 1979.

SALES, Mábia A. Freitas. Negócios e negociantes lusitanos: o comércio dos portugueses em Belém dos meados do Oitocentos. 2017. Tese (Doutorado em História), Universidade Federal Fluminense, Niterói, 2017.

SAMPAIO, Patrícia Melo. Os fios de Ariadne: tipologia de fortunas e hierarquias sociais em Manaus: 1840-1880. Manaus: Universidade do Amazonas, 1997.

SANTOS, Roberto. História econômica da Amazônia (1800-1920). São Paulo: T. A. Queiroz, 1980.

SARGES, Maria de Nazaré. Belém: riquezas produzindo a Belle-Époque (18701912). Belém: Paka-Tatu, 2002.

TOMICH, Dale W. Pelo prisma da escravidão: trabalho, capital e economia mundial. São Paulo: Universidade de São Paulo, 2011.

WALLERSTEIN, Immanuel. The modern world-system I: capitalist agriculture and the origins of the European world-economy in the sixteenth century. Berkley/ Los Angeles/Londres: University of California Press, 2011.

WEINSTEIN, Bárbara. A borracha na Amazônia: expansão e decadência (18501920). São Paulo: Hucitec/Edusp, 1993. 
WILLIAMS, Eric. Capitalismo e escravidão. São Paulo: Companhia das Letras, 2012 .

\section{Fontes}

PARÁ. Falla com que o excellentissimo senhor doutor José Coelho da Gama e Abreu, presidente da provincia, abriu a 2. ${ }^{a}$ sessão da 21. ${ }^{a}$ Legislatura da Assembléa Legislativa da Provincia do Gram-Pará, em 16 de junho de 1879. Pará: [s. n.], 1879.

Falla com que o exm. ${ }^{\circ}$ snr. conselheiro João Silveira de Sousa, abriu a $1 .^{a}$ sessão da 25. " Legislatura da Assembléa Legislativa Provincial, em 15 de outubro de 1884. Belém: Typ. de Francisco da Costa Junior, 1885.

. Falla com que o exm. sr. dr. João Capistrano Bandeira de Mello Filho abrio a $2^{\underline{a}}$ sessão da 20ㅡ Legislatura da Assembléa Legislativa da provincia do Pará, em 15 de fevereiro de 1877. Pará: Typ. do Livro do Commercio, 1877.

- Relatorio apresentado á Assemblea Legislativa da provincia do Pará, na primeira sessão da XVIII Legislatura pelo exm. ${ }^{o}$ snr. presidente da província dr. Francisco Carlos de Araújo Brusque, em 1. ${ }^{\circ}$ de setembro de 1862. Pará: Typ. de F. C. Rhossard, 1862.

. Relatorio com que o exm. sr. dr. José da Gama Malcher, 1vice-presidente, passou a administração da provincia do Pará ao ex. sr. dr. João Capistrano Bandeira de Mello Fitho, em 9 de março de 1878. Pará: Typ. Guttemberg, 1878. 